Visualizing Objects, Places, and Spaces: A Digital Project Handbook

\title{
El Mina Fort: Africa's Oldest Slave Fort
}

Pat Seed, Magda El-Zarki, Alex Longazo, Jessica Kernan

Published on: Sep 03, 2020

DOI: $10.21428 / 51$ bee781.77c63067

License: Creative Commons Attribution 4.0 International License (CC-BY 4.0). 


\section{Team}

Jessica Kernan, Design Consultant

Alex Longazo, Lead Programmer

Patricia Seed, Web Guru, Cartographer, occasional historian, University of California, Irvine

Magda El Zarki, Electrical Engineer, Director of Virtual Environments Research Unit, University of California, Irvine

\section{Project URL}

Website: $\underline{\text { https://www.elminafort.com }}$

\section{Project Abstract}

The bulk of 3D models celebrate imperial cultures but we wanted to illuminate their darker side. This massive slave fort operated continually and longer than any other fort in Africa, trafficking in people since 1482. We believed that a reconstruction of such a long standing slave fort deserved the same attention to detail and craftsmanship as celebratory models of empire. 


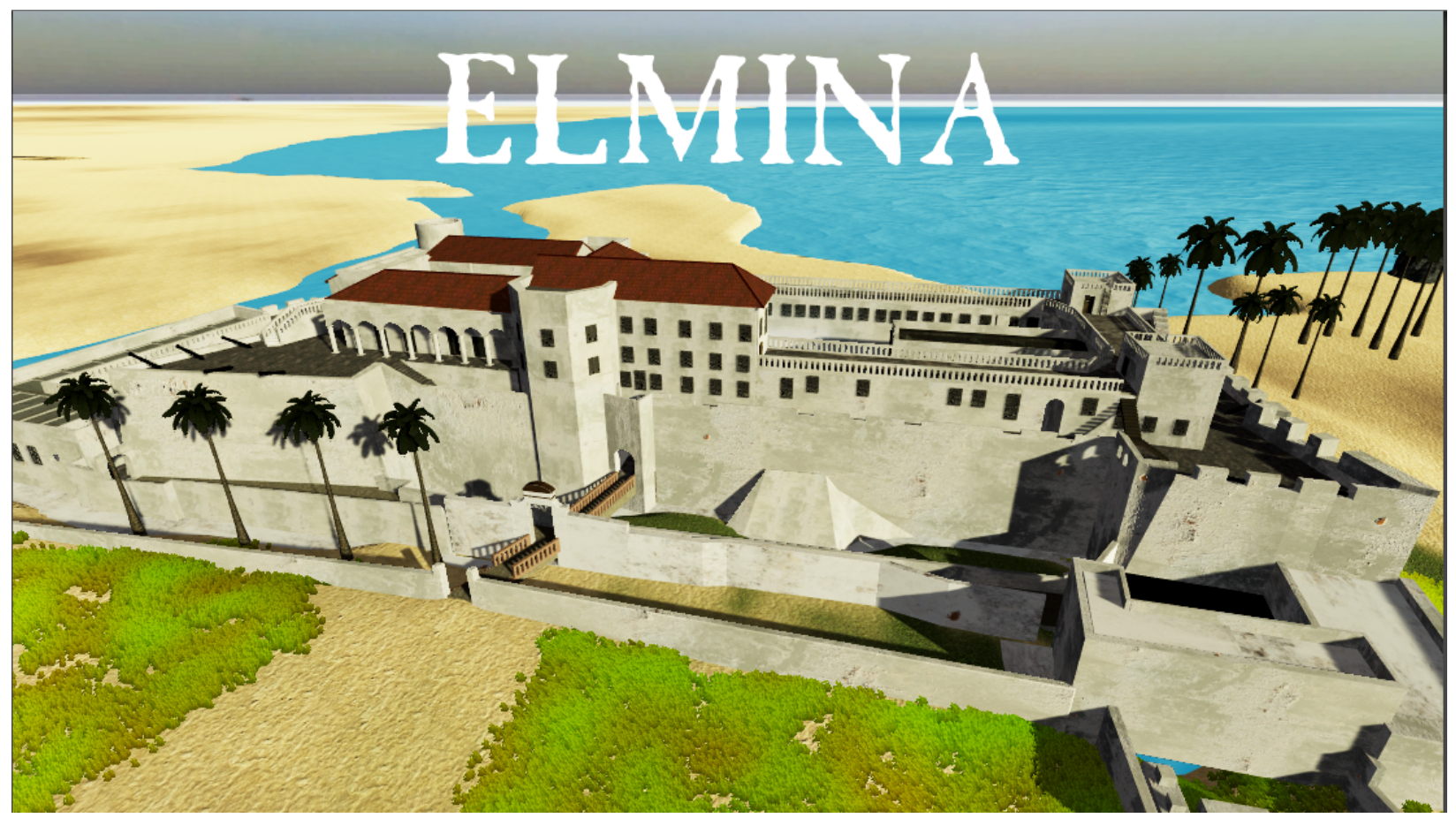

Bird's eye view of the 3D model with "Elmina" written above.

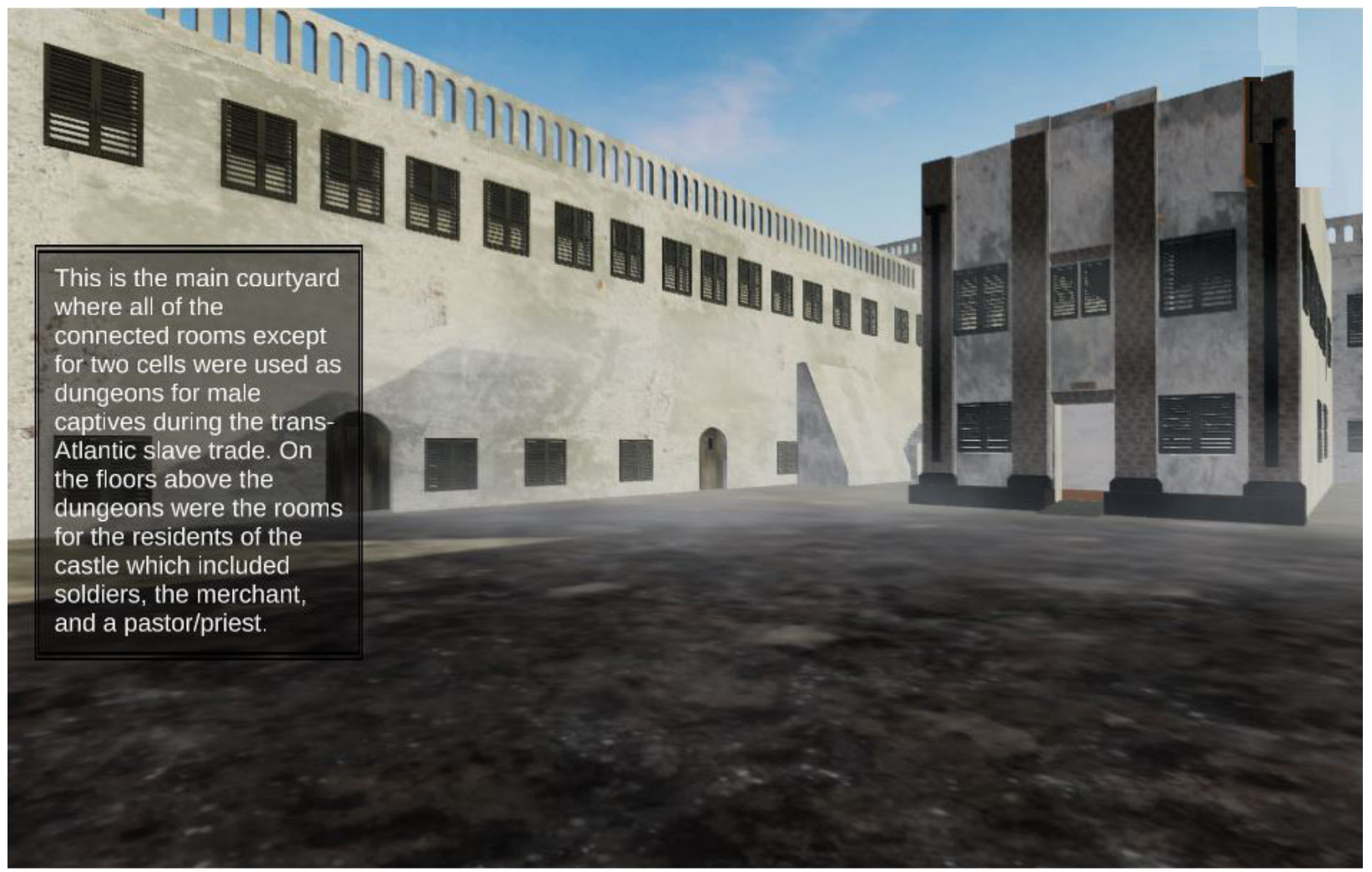

First person view of the original 1482 courtyard. All of the connected rooms except for two prison cells were dungeons holding captives for the slave trade. Above the dungeons large rooms provided quarters the European soldiers, merchants, government
officials, and a pastor/priest." 


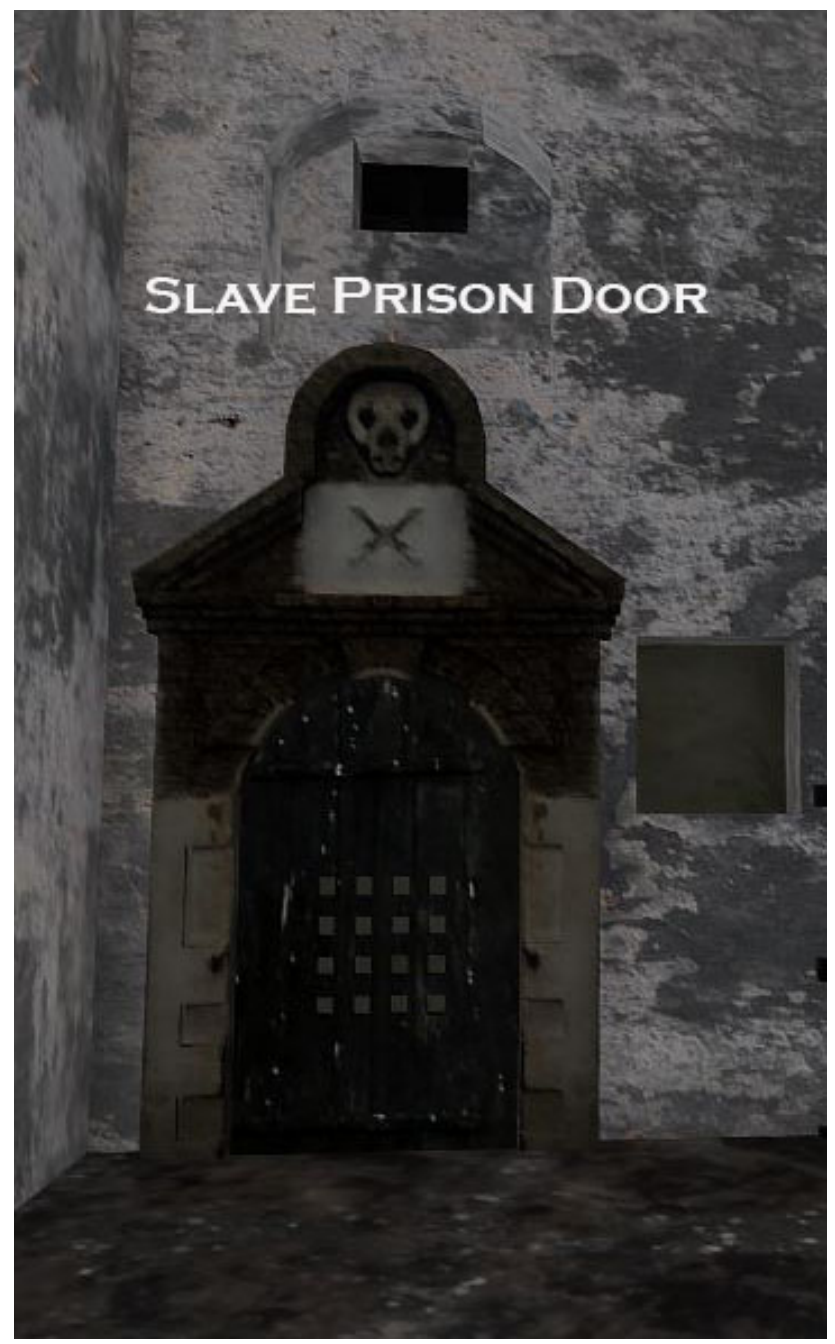

First person view of the "Slave Prison Door." Unlike the adjacent prison for Europeans, this jail has a skull and crossbones telling
everyone that slave prisoners would die.

\section{Time Needed}

When did you begin this project? When did you complete this project?

Time Span: July 1, 2015 - June 30, 2019

Length: 4 years 


\section{Outcomes}

What is the outcome of the project?

The 3D model is readily accessible for teachers and professors and requires no technical knowledge or expertise. The web version will play automatically, thus avoiding the need for downloading onto restricted classroom computers. Recommended for ages 12 years \& older.

\section{Resources}

What tools, resources, programs, or equipment did you use for this project?

At first we used Autodesk 3D Studio Max (3DS Max) to create a 3D exterior of the fort from our spherical photogrammetry. To move inside we employed surface modeling initially using the Unreal Engine which we later abandoned for Unity because of cost and feature availability. The skeleton of the fort is in Unity. Interior features were largely created in Maya , with a small number rendered in 3DS Max. We were fortunate to have a computer lab (evenings and weekends only) provided for free by the Department of Electrical Engineering in addition to a laptop that we purchased.

\section{Funding}

Please describe any costs incurred for this project, and (if relevant) how you secured funding for these costs.

About $\$ 250,000$. This included designing a video game at the same time. We cobbled together grants from the University of California, our campus (Irvine) and from our own pockets.

\section{Workflow}

Please give an overview of the workflow or process you followed to execute this project, including time estimates where possible. 


\section{Time: 2 summers}

A 3 person team created exterior views using spherical photogrammetry, experimenting with $\underline{\text { AutoCad }}$ and $\underline{\text { Sketch Up Pro }}$, but settling on 3DS Max. Additional historical research was also required.

\section{Time: 3.5 years}

Constructing the 3D interior was a learning experience initially with 4 student programmers, numerous art students from local art colleges and high school, an engineer and a geeky web designer. The initial chaos was settled by hiring a prizewinning game designer (Jessica Kernan) who introduced Trello, versioning, deadlines, and deliverables. The team ultimately included two faculty, one staff, and one very talented student programmer (Alex Longazo).

\section{Challenges \& Opportunities}

What, if anything, changed between beginning your project and its current/final form?

We changed computer languages from a $\mathrm{C}++$ based language to a $\mathrm{C} \#$ one, entailing an entire rewrite of every line of code.

We also learned to keep three working updated backups at all times.

Is there anything specific you wish you had known when beginning your project that might help other people to know?

We had no idea of the amount of time, money, and work it would take. Any such project takes a lot of people, a lot of money, and a dedicated leadership team.

\section{Next Steps}

Do you have any plans to follow up on this project or work on something similar in the future?

We would like to model other slave forts: Goree (France), and the sinking Saint James (England). 